Virginia Commonwealth University

VCU Scholars Compass

2012

\title{
Consumers' Choice of Dentists: How and Why People Choose Dental School Faculty Members as Their Oral Health Care Providers
}

\author{
M.Julie Kim \\ Virginia Commonwealth University, mjkim@vcu.edu \\ Peter C. Damiano \\ University of Iowa \\ Jed Hand \\ University of Iowa \\ See next page for additional authors
}

Follow this and additional works at: http://scholarscompass.vcu.edu/genp_pubs

Part of the Dentistry Commons

Reprinted by permission of Journal of Dental Education, Volume 76, 6 (June 2012). Copyright 2012 by the American Dental Education Association.

\section{Downloaded from}

http://scholarscompass.vcu.edu/genp_pubs/3

This Article is brought to you for free and open access by the Dept. of General Practice at VCU Scholars Compass. It has been accepted for inclusion in General Practice Publications by an authorized administrator of VCU Scholars Compass. For more information, please contact libcompass@vcu.edu. 
Authors

M. Julie Kim, Peter C. Damiano, Jed Hand, Gerald E. Denehy, Deborah S. Cobb, and Fang Qian 


\title{
Consumers' Choice of Dentists: How and Why People Choose Dental School Faculty Members as Their Oral Health Care Providers
}

\author{
M. Julie Kim, D.D.S., M.S., M.B.A.; Peter C. Damiano, D.D.S., M.P.H.; \\ Jed Hand, D.D.S., M.H.S.A.; Gerald E. Denehy, D.D.S., M.S.; \\ Deborah S. Cobb, D.D.S., M.S.; Fang Qian, Ph.D.
}

Abstract: This study aimed to better understand how and why people choose dental school faculty members as their oral health care providers. Increasing financial constraints in U.S. dental schools have led their administrators to seek alternative funding sources, one of which can be revenues from dental school faculty practice. To effectively promote faculty practice, it is necessary to understand how and why one chooses a dental school faculty member as his or her oral health care provider. A survey of 1,150 dental school faculty practice patients who recently chose their dentist was conducted, and 221 responded. The information sources these respondents said they used and rated highly were other dentists, friends, family members, clinic website, the Internet, and the insurance directory. Dentist-related attributes that were perceived to be important were quality of care, professional competence of dentist, and explanation of treatment/patient participation in the treatment decision. Dental practice-related attributes perceived to be important were the ability to get appointments at convenient times, reasonable waiting time to get appointments, and attitude/helpfulness of staff. This study found that traditionally popular (family, friends) and newly emerging information sources (the Internet, clinic website, and insurance directory) were both used and perceived to be important by patients of the dental school faculty practice. Dental schools and dentists can use this study's findings to select appropriate communication channels to promote their practices and to focus on attributes that dental consumers value the most.

Dr. Kim is Assistant Professor, Department of General Practice, Virginia Commonwealth University School of Dentistry; she was a resident at the University of Iowa College of Dentistry when this study was conducted; Dr. Damiano is Professor, Department of Preventive and Community Dentistry, University of Iowa College of Dentistry, and Director, University of Iowa Public Policy Center; Dr. Hand is Professor, Department of Preventive and Community Dentistry, and Executive Associate Dean, University of Iowa College of Dentistry; Dr. Denehy is Professor, Department of Operative Dentistry, University of Iowa College of Dentistry; Dr. Cobb is Associate Professor and Graduate Program Director, Department of Operative Dentistry, University of Iowa College of Dentistry; and Dr. Qian is Associate Research Scientist/Adjunct Assistant Professor, Department of Preventive and Community Dentistry, University of Iowa College of Dentistry. Direct correspondence and requests for reprints to Dr. M. Julie Kim, Department of General Practice, School of Dentistry, Virginia Commonwealth University, Lyons Dental Building, 4th Floor, Room \#406, 520 North 12th Street, P.O. Box 980566, Richmond, VA 23298; 804-828-2977 phone; 804-828-3159 fax; mjkim@vcu.edu.

Keywords: faculty, dental school faculty, dental school clinic, clinic management, dentist, dentist selection, health care marketing

Submitted for publication 9/26/11; accepted 4/4/12

$\mathrm{R}$ ecent years have brought about many challenges to U.S. dental schools' finances. Historically, dental schools have depended on outside funding sources such as government appropriations. In 2008, thirty-six out of fifty-six U.S. dental schools received state support. ${ }^{1}$ However, since 1991 state support has not increased sufficiently to keep up with inflation, which has led to a 45 percent purchasing power decrease; as a result, the proportion of total dental school revenue funded by states has declined from 60 percent to 24 to 25 percent. $^{1,2}$ The financial problems of dental schools have significant implications for education, operations, research, and patient care and have forced dental schools to find ways to become more financially independent, including establishment of alternative funding sources. ${ }^{1,2}$ One potential funding source is revenue from patient care, which currently comprises an average of approximately 21 percent of total dental school revenue. ${ }^{3}$ While student clinic expenses exceed revenues by at least 21 percent, ${ }^{1}$ faculty practices consistently generate substantial 
profits. Therefore, dental school administrators may want to explore ways to promote faculty practices.

Although the contribution of faculty practice to the academic mission of dental schools has not received attention in the literature, it is certain that a profitable faculty practice can contribute to a school's financial health. According to the American Dental Association's 2007-08 Survey of Dental Education, the percentages of total revenue from patient care services averaged 20.8 percent in public schools and 22.8 percent in private schools. ${ }^{4}$ Between 2004-05 and 2007-08, the percentage appeared to hold steady or be slightly increasing. In 2007-08, the percentages of total revenue from faculty practice alone averaged 7.0 percent in public schools and 5.9 percent in private schools. At the University of Iowa, where all faculty dentists participate in an intramural faculty practice, faculty practice revenue in FY 2010 comprised 23.7 percent of the total revenue, highest among all revenue sources. ${ }^{5}$

In most dental schools with an intramural faculty practice, the revenues from the faculty practice contribute to the dental school. In a survey of finance officers in twenty-five U.S. dental schools in 2010 , 71 percent of the dental school faculty practices were found to belong to the dental school, and 92 percent of the responding dental schools reported that faculty practice revenues are used to augment faculty salary and/or to supplement dental school financing. ${ }^{6}$

To study dental consumers' choice of dentists, it is important to note that consumer decision making typically happens in sequenced stages. Kotler's fivestage model of the consumer buying process explains this staged sequence well (Figure 1). ${ }^{7}$ The buying process starts with problem recognition, then passes through the stages of information search, evaluation of alternatives, purchase decision, and post-purchase behavior. During this process, a dental consumer narrows down his or her choice from total set (all dentists in the area) to choice set (a few dentists whom the consumer seriously considers). Figure 2 summarizes how Kotler's model can be applied to dentist selection process. In order to effectively promote faculty practices, dental school administrators need to understand how and why potential dental consumers choose dental school faculty for their oral care. How includes what information sources are available and are used to select a dentist before the patient's first visit. Why includes the evaluation criteria consumers use and the attributes they prefer.

A commonly accepted categorization divides information sources into personal, commercial, and public information sources. ${ }^{8}$ Personal information sources (i.e., word of mouth) include family, friends,

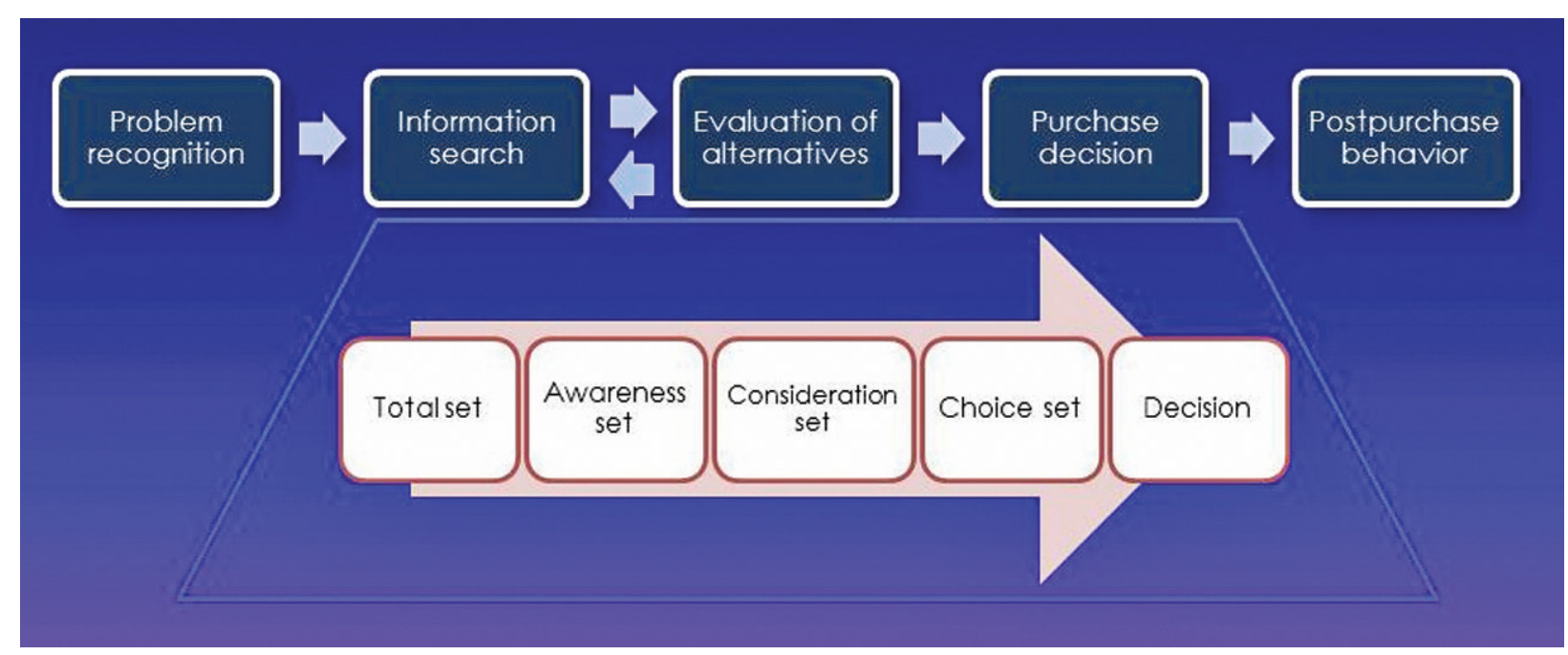

Figure 1. Conceptual framework for decision making: Kotler's five-stage model of the consumer buying process

Source: Adapted from Kotler P. Analyzing consumer markets and buyer behavior. In: Kotler P, ed. A framework for marketing management. New York: Prentice Hall, 2001:98. 


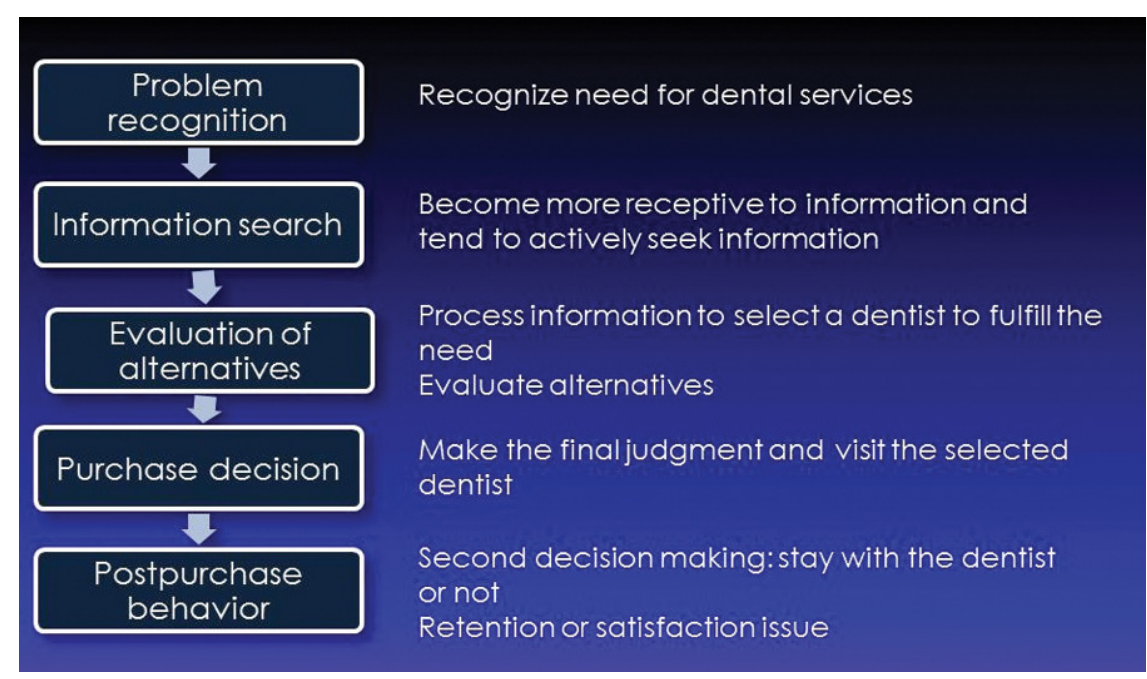

Figure 2. Application of Kotler's model to dentist selection process

and professional referrals - the most often cited information sources in selecting a dentist. ${ }^{8}{ }^{8}$ Word of mouth is often cited as the most powerful and influential information source. Commercial information sources include mass media advertisements such as newspaper ads, yellow pages, radio or TV commercials, and printed brochures or pamphlets. Commercial information sources can be readily available and accessible, and most consumers are aware of them. ${ }^{8}$ However, commercial information sources are impersonal and targeted at the general public rather than individuals, which makes them less influential. An emerging form of commercial information source is the dental clinic website. Although the number of dentists who use a clinic website to provide information to patients seems to be increasing, few studies have examined their use and influence as related to consumer decision making.

Public information sources are defined as impersonal or neutral information sources. ${ }^{10,11}$ This type of information source includes technical reports, magazine articles, professional organizations, government sources, the Internet, and reports written by knowledgeable third-party agencies such as Consumer Reports magazine. ${ }^{10,11}$ In the dental services market, consumers' awareness and use of public information sources seem to be relatively low. ${ }^{9}$

A number of published studies have addressed the question of why patients choose a particular den- tist - that is what attributes (preferences) of a dentist or dental office a patient weighs more heavily when he or she selects a dentist. Mangold et al. found that quality of work, dentist's concern for patients, price, personal appearance, office location, waiting time to see the dentist, and insurance form preparation were important factors in the decision making. ${ }^{12}$ Book and Stockton concluded that referrals from friends and relatives and convenient office location were the two most important influencing factors. ${ }^{13}$ Chakraborty et al. used conjoint analysis to determine tradeoffs among multiple attributes and found that sensitivity to the patient's concerns was the most important attribute followed by assigned dentist (being able to be seen by the same dentist) and dental office appearance. ${ }^{14}$

Little information is available regarding dental consumers' choice of dental school faculty practice. Therefore, the present study aimed to better understand how and why patients choose dental school faculty members as their oral health care providers. This study examined how and why new dental faculty practice patients of the University of Iowa College of Dentistry (UI COD) chose their dentist. The insights obtained from this study can benefit dental schools and dentists by helping them to reach out to the community more strategically and increase awareness of dental school clinics and services both by licensed practitioners and students. This will result 
in increased revenues for the dental school to fulfill its mission more sustainably and more opportunities to learn for students.

\section{Methods}

This study was an observational, descriptive study of the UI COD's new faculty practice patients who met the study's inclusion criteria. The study was approved by the University of Iowa Institutional Review Board (IRB) in August 2010. The paper-based questionnaire was mailed to the subjects, and data were collected in September and October 2010.

The study population consisted of patients who made their first visit to the COD faculty practice during calendar year 2009. Only patients aged eighteen years or older at the time of the first visit were included. Patients were verified as having been seen by a faculty provider at their first visit when their first visit was documented with the exam codes of D0140 Limited Oral Evaluation and/or D0150 Comprehensive Oral Evaluation. A total of 1,150 patients were identified using the COD's electronic medical record system, AxiUm.

The questionnaire consisted of four sections: general questions, information sources, dentist and dental practice attributes, and demographics. The first section included general questions such as whether the patient selected UI COD in general or a particular dentist first. The second section included questions regarding information sources. A list of sixteen information sources was generated from the previous literature. The sixteen information sources were classified into three categories: personal, commercial, and public information sources. For each information source listed, survey respondents were first asked whether they actually used the information source and then were asked to indicate how important the information source was in the selection process on a five-item, gradually ascending anchor scale: not important at all, not very important, neutral, important, and very important. The instructions in the heading of this section clearly stated, "Please rate the source only if you used it" (Figure 3). The third section was about dentist and dental practice attributes. The lists of twelve dentist-related attributes and thirteen dental practice-related attributes were generated from the previous literature. The survey respondent was asked to rate each attribute on a five-item, gradually ascending anchor scale: not important at all, not very important, neutral, important, and very important. The last section asked for demographic information such as gender, age, highest education level, health care-related profession, and if the respondent had dental insurance.

The questionnaire was mailed to patients' addresses obtained from the UI COD's patient registration file. Three weeks later, a follow-up letter was sent to those who had not returned the survey. A total of 1,150 questionnaires were distributed, and 221 responded, resulting in the response rate of 19 percent. The characteristics of the 221 respondents were compared to that of the overall study population using patient registration information. In general, age and gender distribution was similar for the respon-

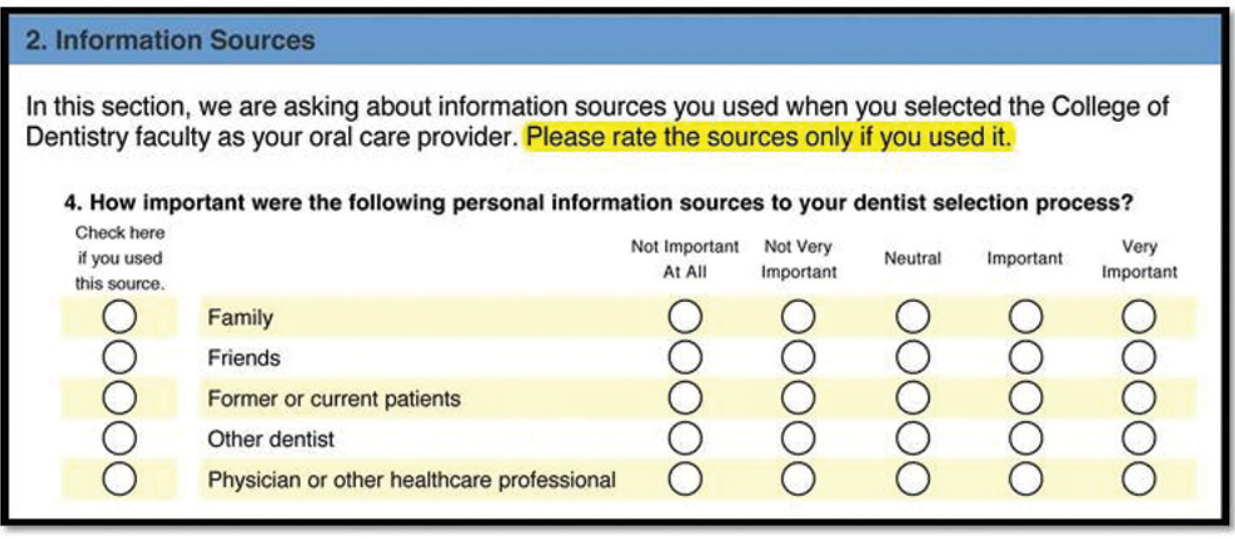

Figure 3. Information sources section of the questionnaire 
dents and the entire group. To measure perceived importance of information sources that were actually used, the respondents were asked to rate the information sources only when they indicated they used it. However, 33 to 43 percent of the ratings were not preceded with the indication of "used," which made the validity of the rating questionable: some respondents may have rated an information source although they did not use it. Since the intention of the information sources section was to find out how the new patients selected their dentist in an actual rather than hypothetical situation, we decided to discard ratings without the indication of "used," which resulted in the sample size of the information sources ratings decreasing significantly.

\section{Results}

Sixty-three percent of the survey respondents were female, and 37 percent were male. Twenty-nine percent were between eighteen and thirty years of age, while 21 percent were in the sixty and older age group. The mean age was forty-three, ranging from eighteen to ninety-one years. The vast majority of the respondents ( 80 percent combined) had a college or graduate degree: 34 percent college and 46 percent graduate degree (Table 1). Forty-two percent of the respondents said they had worked or were currently working in a health care-related field, and 71 percent reported having private dental insurance. Only 5 percent said they have Title XIX benefits (Medicaid of the state of Iowa). Seventy-two percent responded that they selected the COD in general, while 27 percent said they chose a specific dentist who practices in the COD.

We summarized the respondents' use of information sources in ranked order (Table 2). Among the personal information sources, the respondents rated other dentists, friends, and family the highest, at 27 percent, 24 percent, and 20 percent, respectively. Among the commercial information sources, the clinic website was ranked highest, with a percentage of use at 21 percent. In the category of public information sources, the Internet and insurance directory were said to be used most frequently, at 17 percent and 15 percent, respectively.

We combined the frequencies of ratings of "important" and "very important" only for the respondents who indicated they had used the information source (Table 2). In the category of personal information sources, the respondents rated other

\begin{tabular}{|c|c|c|}
\hline Variable & Number & $\begin{array}{l}\text { Valid } \\
\text { Percentage }\end{array}$ \\
\hline \multicolumn{3}{|l|}{ Gender $(\mathrm{N}=216)$} \\
\hline Female & 136 & $63 \%$ \\
\hline Male & 80 & $37 \%$ \\
\hline \multicolumn{3}{|l|}{ Age $(\mathrm{N}=212)$} \\
\hline 18 to 29 years & 61 & $29 \%$ \\
\hline 30 to 39 years & 53 & $25 \%$ \\
\hline 40 to 49 years & 26 & $12 \%$ \\
\hline 50 to 59 years & 28 & $13 \%$ \\
\hline 60 years and over & 44 & $21 \%$ \\
\hline \multicolumn{3}{|l|}{ Education Level $(\mathrm{N}=216)$} \\
\hline Less than high school diploma & 2 & $1 \%$ \\
\hline High school diploma & 42 & $19 \%$ \\
\hline College degree & 73 & $34 \%$ \\
\hline Graduate degree & 99 & $46 \%$ \\
\hline \multicolumn{3}{|c|}{ Health Care-Related Profession (N=215) } \\
\hline Yes & 90 & $42 \%$ \\
\hline No & 125 & $59 \%$ \\
\hline \multicolumn{3}{|l|}{ Dental Insurance (N=215) } \\
\hline Private dental insurance & 152 & $71 \%$ \\
\hline Title XIX (lowa Medicaid) & 10 & $5 \%$ \\
\hline No dental insurance & 53 & $25 \%$ \\
\hline \multicolumn{3}{|l|}{$\begin{array}{l}\text { Seeking Care from Specific Dentist } \\
\text { or Dental School in General }(N=217)\end{array}$} \\
\hline $\begin{array}{l}\text { Specific dentist who practices in } \\
\text { the College of Dentistry }\end{array}$ & 59 & $27 \%$ \\
\hline College of Dentistry in general & 158 & $72 \%$ \\
\hline \multicolumn{3}{|c|}{$\begin{array}{l}\text { Note: Due to missing data, not all variables add up to the total } \\
\text { sample size of } 221 \text {. Percentages may not total } 100 \text { percent } \\
\text { because of rounding. }\end{array}$} \\
\hline
\end{tabular}

dentists, friends, and family "important" or "very important" by fifty-two, forty-four, and thirty-nine of the fifty-nine, fifty-two, and forty-three respondents, respectively. In the category of the commercial information sources, thirty-four respondents out of fortyfive rated the clinic website as "important" or "very important." In the category of public information sources, the Internet and the insurance directory were rated "important" or "very important" by twenty-nine and twenty-nine out of thirty-seven and thirty-three respondents, respectively.

The combined frequencies of important and very important for each dentist attribute were also organized in rank order (Table 3). Quality of care, professional competence of dentist, and explanation of treatment were highly ranked, while personal ap- 


\begin{tabular}{|c|c|c|}
\hline Information Source & "Used" & Combined Very Important and Important \\
\hline \multicolumn{3}{|l|}{ Personal Information Source } \\
\hline Other dentist & $59(27 \%)$ & $52(95 \%)$ \\
\hline Friends & $52(24 \%)$ & $44(88 \%)$ \\
\hline Family & $43(20 \%)$ & $39(93 \%)$ \\
\hline Former/current patient & $27(12 \%)$ & $27(100 \%)$ \\
\hline Physician or other health care professional & $15(7 \%)$ & $15(100 \%)$ \\
\hline \multicolumn{3}{|l|}{ Commercial Information Source } \\
\hline Clinic website & $45(21 \%)$ & $34(76 \%)$ \\
\hline Yellow pages & $6(3 \%)$ & $3(50 \%)$ \\
\hline Brochure/pamphlet & $5(2 \%)$ & $5(100 \%)$ \\
\hline Magazine/newspaper advertisement & $1(1 \%)$ & 0 \\
\hline \multicolumn{3}{|l|}{ Public Information Source } \\
\hline Internet & $37(17 \%)$ & $29(81 \%)$ \\
\hline Insurance directory & $33(15 \%)$ & $29(94 \%)$ \\
\hline Others & $15(7 \%)$ & $9(60 \%)$ \\
\hline Heard doctor speak & $10(5 \%)$ & $7(88 \%)$ \\
\hline Dental associations & $7(3 \%)$ & $5(100 \%)$ \\
\hline City or county health services & $4(2 \%)$ & $2(100 \%)$ \\
\hline Magazine/newspaper article & $2(1 \%)$ & 0 \\
\hline
\end{tabular}

pearance of dentist, whether the dentist is a member of a dental association, and dental school attended were ranked low.

Finally, we combined the frequencies of "important" and "very important" for each dental practice attribute in rank order (Table 4). The ability to get appointments at convenient times, a reasonable waiting time to get appointments, and the attitude/helpfulness of staff were highly ranked, while parking, atmosphere/appearance of the office, and whether the dentist accepts credit cards or provides credit were ranked low.

\section{Discussion}

This study generated information about how and why patients chose a dental school faculty practice and faculty dentist as their oral health care provider, including the information sources used and their perceived importance (the second step in the five-stage consumer buying decision process; Figure 1) and the perceived importance of attributes of the dentist and the dental practice (the third step). To our knowledge, no previous studies have examined this issue. The ultimate intention of this study was to explore how and why patients choose a dentist in a dental school faculty practice clinic, to provide some descriptive information, and to develop a framework for future research. This study was not intended to provide a definitive model to explain dentist selection behavior or to develop a predictive model for future behavior.

The ideal population for this study would have been those who had recently selected a dentist but not yet made the first visit. If they made the choice a long time ago, they may not recall correctly how and why they selected a particular dentist, considering the recall bias. Since we limited the study population to new patients who had selected a dentist approximately within the past year, we believe that we were able to reduce recall bias to an extent compared to other studies that did not limit their study populations by when the respondents selected a dentist.

In studying human behavior, it is generally believed that information about what actually happened is more valid for predicting future behavior than information about what would happen in a hypothetical situation. This study was trying to gain information about what actually happened in the dentist selection process. For example, the information sources section of the questionnaire had two separate columns: the left column of each listed information source asked respondents to indicate if they used the particular 
Table 3. Responses to question "Please indicate how important each [dentist] attribute listed below was in deciding to come to a faculty dentist at the College of Dentistry," by combined score and ranking

\begin{tabular}{|c|c|c|c|}
\hline Dentist Attribute & Important & $\begin{array}{c}\text { Very } \\
\text { Important }\end{array}$ & $\begin{array}{l}\text { Combined Important } \\
\text { and Very Important }\end{array}$ \\
\hline Quality of care $(\mathrm{N}=207)$ & 45 & 145 & $190(92 \%)$ \\
\hline Professional competence of dentist $(\mathrm{N}=206)$ & 43 & 143 & $186(90 \%)$ \\
\hline Explanation of treatment/you participate in the treatment decision $(\mathrm{N}=206)$ & 63 & 114 & $177(86 \%)$ \\
\hline Dentist provides personal attention to diagnosis and aftercare $(\mathrm{N}=206)$ & 78 & 94 & $172(83 \%)$ \\
\hline Dentist uses most up-to-date techniques & 76 & 88 & $164(81 \%)$ \\
\hline Dentist's concern for patients/sensitivity (responds to your pain and fear) $(\mathrm{N}=201)$ & 71 & 85 & $156(78 \%)$ \\
\hline Reputation of the dentist (recommendation) $(\mathrm{N}=201)$ & 64 & 77 & $141(70 \%)$ \\
\hline The dentist is in my insurance network $(\mathrm{N}=202)$ & 42 & 98 & $140(69 \%)$ \\
\hline Number of years in experience $(\mathrm{N}=197)$ & 80 & 32 & $112(57 \%)$ \\
\hline Personal appearance of dentist $(\mathrm{N}=199)$ & 59 & 22 & $81(41 \%)$ \\
\hline Whether the dentist is a member of a dental association $(\mathrm{N}=197)$ & 41 & 19 & $60(30 \%)$ \\
\hline Dental school attended $(\mathrm{N}=197)$ & 36 & 11 & $47(24 \%)$ \\
\hline
\end{tabular}

Table 4. Responses to question "Please indicate how important each [dental practice] attribute listed below was in deciding to come to a faculty dentist at the College of Dentistry," by combined score and ranking

Dental Practice Attribute

\begin{tabular}{ccc} 
Important & $\begin{array}{c}\text { Very } \\
\text { Important }\end{array}$ & $\begin{array}{c}\text { Combined Important } \\
\text { and Very Important }\end{array}$ \\
\hline 100 & 68 & $168(82 \%)$ \\
103 & 61 & $164(82 \%)$ \\
107 & 48 & $155(78 \%)$ \\
96 & 52 & $148(74 \%)$ \\
73 & 73 & $146(73 \%)$ \\
93 & 52 & $145(71 \%)$ \\
73 & 67 & $140(70 \%)$ \\
78 & 59 & $137(69 \%)$ \\
94 & 43 & $137(69 \%)$ \\
75 & 43 & $118(60 \%)$ \\
80 & 25 & $105(52 \%)$ \\
68 & 15 & $83(42 \%)$ \\
40 & 21 & $61(31 \%)$
\end{tabular}

information source, then the corresponding right column asked them to rate it only when they indicated they used it. By directing the respondents to limit their information source ratings to the ones they used, we expected to gain insight into what actually happened.

\section{Patient Characteristics}

The survey respondents' demographic characteristics are worth discussing further. The mean age of the respondents was forty-three years, and the median was thirty-eight years, indicating the respondents were relatively young. A vast majority of the respondents (81 percent) reported having a college or graduate level degree, which is different from the demographics of participants in other studies. This higher level of education may reflect the fact that the UI COD is located in a college town where many community residents have advanced degrees. In a similar sense, we expected that many of the respondents would be working in a health profession since the UI COD is located in a large health care complex. Overall, this expectation was realized, with over 40 percent of the respondents reporting that they work or have worked in a health care-related profession. In terms of dental insurance, the vast majority (71 percent) of the respondents said that they have private dental insurance, which certainly shows that the faculty practice patients differ from dental school clinic patients. Damiano and Warren's study, for example, 
reported that only an average of 16 percent of clinic patients at six dental schools said they were planning to pay with private dental insurance. ${ }^{15}$

Seventy-two percent of our respondents indicated that they had selected the COD in general rather than a specific dentist who practices in the COD (Table 1). This could be explained partially by the fact that approximately 20 percent of new patients are University of Iowa employees or their dependents. University employees may have selected COD rather than a specific dentist due to convenience and visibility. In addition, it should be noted that the general reputation of the dental school may encourage potential dental consumers to choose a dental school faculty dentist. This situation would be different from private dental practices in which the reputation of a dentist and that of his or her dental practice are generally considered the same, especially for solo private practitioners.

\section{Information Sources}

Other dentists, friends, and family members (personal information sources) were used by about one-quarter of the respondents for selecting a dentist. This finding is somewhat different from the traditional belief and the findings of other studies that family or friends were the most frequently used and the predominant information source in dentist or physician selection. Mangold et al. reported 83.7 percent of new community residents surveyed said they used "friends or acquaintances" as guides to dentist selection, followed by 63.8 percent who used "members of family."12 It is interesting to note that, in Mangold et al.'s study, 46.9 percent of the respondents said that they used the Yellow Pages compared to our finding of only 3 percent who used that source. One possible explanation of this discrepancy is that the Internet and clinic websites may have replaced Yellow Pages as sources of information. Mangold et al.'s study was published in 1986 when the Internet was not very widely available. In our study, 17 percent and 21 percent of the respondents indicated that they used the Internet and the clinic website, respectively.

Personal information sources such as other dentists, friends, and family were highly rated by the respondents who used them, similar to Book and Stockton's study in which 35.7 percent of the respondents reported that recommendations of friends or relatives were the most influential factor. ${ }^{13}$ Prior to this study, we were not sure how many potential dental consumers would rely on web-based informa- tion sources for the dentist selection process because dental consumers have been believed to heavily rely on word of mouth from personal sources. Interestingly, our study found that dental consumers not only used the web-based information sources heavily but also perceived them to be important. In addition to the timing of this study, the high education level of this population may have led them to be more web-savvy and comfortable using a computer for significant decisions. It is also interesting to note that information sources with higher use were also given high ratings. We can interpret this as suggesting that dental consumers use information sources that they consider important.

\section{Dentist and Dental Practice Attributes}

In our study, dentist attributes such as quality of care, professional competence of the dentist, and explanation of treatment were rated high in the combined frequency of "important" and "very important." Dental practice attributes such as ability to get appointments at convenient times, reasonable waiting time to get appointments, and attitude/helpfulness of staff were highly rated in the combined frequency of "important" and "very important." Our findings are similar to previous studies' findings with some variations. A number of studies found the attribute of quality of care to be the most important, ${ }^{12,16,17}$ although the definition of quality can vary greatly. Professional competence ${ }^{17}$ and explanation of treatment ${ }^{14,17}$ were also found to be important in other studies. In terms of dental practice attributes, the ability to get an appointment at convenient times was found to be important in Manski's study, ${ }^{17}$ as was a reasonable waiting time in Mangold et al.'s study. ${ }^{12}$ The attribute of attitude/ helpfulness of staff was found to be important in our study, but it was not highly rated in Chakraborty et al.'s conjoint analysis, in which it was ranked eighth of twenty-four attributes. ${ }^{14}$

It is interesting to note that some attributes other studies found important were not rated highly in our study. The attribute of dentist's concern for patients/sensitivity, for example, was rated very highly in other studies, ${ }^{12,14}$ but was ranked sixth of twelve dentist attributes in our study. The attribute of reputation of the dentist was also highly rated in other studies, ${ }^{13,16,17}$ but was ranked seventh of twelve dentist attributes in our study. The latter can be explained by the fact that 72 percent of the respondents in our study had selected the COD in general rather than a 
specific dentist, so it was the reputation of the COD as a whole that mattered to them in the initial decision rather than that of any particular practitioner.

There are some limitations of this study that should be taken into consideration when applying its findings. First, the study respondents had recently chosen a dentist but had had various levels of post-selection experience with their chosen dentist. Information obtained from the direct post-selection experience would not be available to potential dental consumers who are in the dentist selection process and thus constitute the target group for a dental school or dentist who wants to attract new patients. Future studies could examine those who have recently selected a particular dentist but not yet visited the chosen dentist in order to gain more understanding about the initial dentist selection process.

Second, this study was conducted with a paperbased questionnaire that did not allow incorporating complex skip patterns. In the information sources section, 33 to 43 percent of the ratings were not accompanied by the corresponding indication of "used it" although respondents were supposed to rate only the ones they used. Apparently some respondents rated ones they did not use or, at least, did not indicate "use." We discarded those responses in our analysis because there was no way to determine if those respondents had indeed used the source even if they did not indicate they had. Omitting those responses thus helped us maintain the internal validity of the study. An online survey's skip pattern would require the respondents to rate only the ones they indicated use, but unfortunately we could not conduct an online survey because only 20 percent of the study population had an e-mail address in their records. On a similar point, data in the dentist and dental practice attributes section could be biased to a certain extent. The introductory paragraph stated "We are seeking information ... that you might have considered ... BEFORE your first visit" with the intention of directing respondents to rate attributes that they actually considered before they made the first visit. However, it is possible that the respondents rated all attributes regardless of whether they had actually considered those attributes. Future studies would ideally take advantage of electronic questionnaires to obtain cleaner data.

Third, to be more representative, we decided to study the entire new patient pool of the UI COD faculty practice in CY 2009 instead of sampling. However, the 19 percent response rate makes it harder to exclude non-respondent bias and to consider the respondents as being truly representative of the UI COD 2009 new patients. Finally, although this study's findings are applicable to many dental school faculty practices and to private practices to a certain extent, a dental school or dentist that wants to promote a practice may want to consider examining their own target group to obtain information directly relevant to their situation. In the present study, the study population was mainly college town residents who tend to be highly educated and have higher income and may not be representatives of dental practice patients in general.

\section{Conclusions}

The main findings of this study can be summarized as follows. The UI COD's new patients used both traditional and recently emerging information sources. Highly used information sources included friends, other dentists (traditional), the clinic website, the Internet, and insurance directory (recently emerging). These highly used information sources were also perceived by the respondents to be important. In terms of why they chose a UI COD faculty dentist, a number of dentist and dental practice attributes were considered important to these new patients. These attributes included quality of care, professional competence of dentist, ability to get appointments at convenient times, and reasonable waiting time to get appointments. A dental school or dentist who wants to promote a practice can better communicate with potential new patients and improve attributes that are important to them using this study's findings.

\section{Acknowledgments}

This study was supported by University of Iowa College of Dentistry internal funding. Sincere gratitude is expressed to College of Dentistry staff members in Dental Informatics and Clinic Administration, especially to Ms. Becky Todd.

\section{REFERENCES}

1. Formicola AJ, Myers R, Hasler JF, Peterson M, Dodge W, Bailit HL, et al. Evolution of dental school clinics as patient care delivery centers. J Dent Educ 2006;70(12):1271-88.

2. Bailit HL. The fundamental financial problems of dental education and their impact on education, operations, scholarship, and patient care. J Dent Educ 2008;72(2 Suppl):14-7.

3. Bailit HL, Beazoglou TJ, Formicola AJ, Tedesco LA, Brown LJ, Weaver RG. U.S. state-supported dental schools: financial projections and implications. J Dent Educ 2008;72(2 Suppl):98-109. 
4. American Dental Association. Revenue from patient care services. In: Survey of dental education, 2007-08. Chicago: American Dental Association, 2009:16-40.

5. University of Iowa College of Dentistry. Summary of financial resources. Iowa City: University of Iowa College of Dentistry, forthcoming.

6. Kim MJ, Hand J, Arneson S. 2010 survey to ADEA business and financial administration section: dental school faculty practice. Unpublished manuscript.

7. Kotler P. Analyzing consumer markets and buyer behavior. In: Kotler P, ed. A framework for marketing management. New York: Prentice Hall, 2001:98.

8. Mangold WG, Abercrombie CL, Berl R, Pol L. Reaching patients who are new to the community. J Dent Pract Admin 1990;7(2):79-84.

9. Garry JF. How (and why) patients choose a dentist - and stay with him. Orange County Dental Society Bulletin, November 1972:5,passim.

10. Hekmat F, Farris R, Dunning D. Information source preferences for selecting dental services among elderly consumers. Health Marketing Q 1998;16(1):79-92.
11. Beltramini RF, Sirsi AK. Physician information acquisition and believability: a field experiment on source and type of information. J Health Care Marketing 1992;12(4):52-9.

12. Mangold WG, Pol L, Abercrombie CL, Berl R. New community residents' preferences for dental service information. J Am Dent Assoc 1986;112(6):840-3.

13. Book DS, Stockton HJ. Why patients choose a particular dentist. J Can Dent Assoc 1986;52(2):123-6.

14. Chakraborty G, Gaeth GJ, Cunningham M. Understanding consumers' preferences for dental service. J Health Care Marketing 1993;13(3):48-58.

15. Damiano PC, Warren JJ. A profile of patients in six dental school clinics and implications for the future. J Dent Educ 1995;59(12):1084-90.

16. Cunningham MA, Gaeth GJ. Using importance-performance analysis to assess patients' decisions to seek care in a dental school clinic. J Dent Educ 1989;53(10):584-6.

17. Manski RJ. Decision process of the dental consumer. J Dent Pract Admin 1989;6(1):35-8. 